Anuario Latinoamericano

Ciencias Políticas

y Relaciones Internacionales

vol. 10,2020

pp. $147-166$

\section{A cultura chinesa: das dimensões culturais de Hofstede às perspectivas asiacêntricas de comunicação}

DOI:10.17951/al.2020.10.147-166

\section{Chinese Culture: From Hofstede's Cultural Dimensions to Asiacentric Communication Perspectives}

\author{
Manuel Duarte João Pires* \\ SUN YAT-SEN UNIVERSITY \\ ZHUHAI, GUANGDONG, CHINA \\ $\triangle$ mdjpires@mail.sysu.edu.cn \\ https://orcid.org/0000-0002-1242-5319
}

\section{RESUMO}

Numa época em que a China assume um papel cada vez mais influente na geoestratégia mundial, sobretudo através do poderio económico e diplomático, persiste ainda algum desconhecimento sobre a cultura chinesa (Jullien, 2010). O objetivo deste artigo é contribuir para a compreensão dos valores da cultura chinesa analisando os conceitos de cultura e de comunicação na sociedade chinesa à luz das dimensões culturais preconizadas por Hofstede e das perspectivas "asiacêntricas" defendidas por Miike. Com base na interpertação destes conceitos, o presente estudo defende que o desenvolvimento de competências comunicativas e interculturais se apresenta como um meio indispensável não só para conhecer a cultura chinesa sem uma abordagem apriorística ou estereotipada mas também para o sucesso do diálogo entre culturas e povos, tão premente nos dias que correm.

PALAVRAS-CHAVE: China, cultura, comunicação, interação, harmonia.

\begin{abstract}
At a time when China is assuming an increasingly influential role in world geostrategy, especially through economic and diplomatic power, there is still some ignorance about Chinese culture (Jullien, 2010). The aim of this article is to contribute to the understanding of the values of Chinese culture by reviewing the concepts of culture and communication in Chinese society based on the cultural dimensions advocated by Hofstede and on Miike's "Asiacentric" perspectives. Based on the interpretation of
\end{abstract}

* Leitor de Português. Estudante de doutoramento (Universidade de Lisboa). Áreas de investigação: Português na China, Estudos Interculturais, Português Língua Não Materna. 
Dossier América Latina: la iniciativa china de la Franja y la Ruta these concepts, the present study argues that the development of communicative and intercultural competences is crucial not only to approach Chinese culture without generalizations or stereotyped insights but also for the benefit of dialogue between cultures and nations, so imperative these days.

KEYWORDS: China, culture, communication, interaction, harmony.

\section{Introdução}

Em convergência com as palavras de Hall (1959), defendendo que as culturas escondem muito mais do que revelam, o objetivo deste trabalho é analisar comparativamente diferentes visões e interpretações teóricas sobre a cultura chinesa, tendo como referência o conceito de comunicação na cultura chinesa, com vista a contribuir para o conhecimento da cultura e para o decorrente desenvolvimento de competência intercultural no diálogo com este país asiático. Segundo Jullien (2010) conhecer o Outro é humanizar e ampliar a moral, restabelecendo a possibilidade da sua refundação e permitindo buscar uma moral que admita a crítica da suspeita, pois para conhecer o Outro é necessário sair da indiferença mútua e efetuar uma mudança de foco que suscite o pensar. O presente trabalho pretende fomentar o diálogo e o entendimento, uma vez que a China, tal como enfatiza Jullien (2010), representa um caso "particularmente tipificado e com forte exterioridade em relação à cultura europeia” (p.1) porque os ocidentais muitas vezes "não compreendem as visões dos orientais" (p.5). Sendo a interculturalidade, atualmente, cada vez mais um imperativo do modo de vida do mundo atual e estando a China comprometida em sedimentar relações de vária ordem a nível global, nomeadamente através do programa Uma Faixa, Uma Rota (em inglês: One Belt One Road), este artigo pretende trazer luz a algumas particularidades da cultura chinesa e contribuir para a compreensão e interação entre a China e os demais países, dirigindo-se a todos os que interagem ou pretendem interagir com a cultura chinesa. Para tal, serão analisadas diferentes perspectivas teóricas, começando pelas dimensões culturais de Hofstede (2001) no que respeita à sociedade chinesa, bem como os estudos de autores asiáticos como Huang (2000), C. Chang (2007), Y. Chang (2008), Wang (2008) e Miike (2012) que se debruçam sobre os conceitos de comunicação e cultura a partir de uma visão asiática. Por fim, serão analisadas as teorias de Alsina (1999; 2004), UNESCO (2009), Saint-Jacques (2012) ou Jandt (2015) sobre a importância de desenvolver competências de comunicação intercultural para dialogar e interagir no mundo de hoje. 


\section{A cultura chinesa segundo as dimensões culturais de Hofstede}

De acordo com Hofstede $(2001 ; 2012)$ para compreender a cultura de um determinado país existem cinco dimensões culturais que se devem analisar, isto é, cinco "aspetos da cultura que podem ser medidos em relação a outras culturas" (Hofstede, 2012, p. 23). Estas cinco dimensões são: Distância do Poder, Aversão à Incerteza, Individualismo versus Coletivismo, Masculinidade versus Feminilidade, Orientação a Longo Prazo versus Orientação a Curto Prazo. Segundo Hofstede Insights (2018), o autor introduziu recentemente uma sexta dimensão denominada Indulgência versus Repressão.

Com base em Hofstede (2012), a dimensão Distância do Poder pode ser entendida através da forma como os membros menos poderosos das instituições e organizações de um país esperam e aceitam que o poder seja distribuído de forma desigual, uma vez que todas as sociedades se deparam com a questão do poder e da desigualdade. A dimensão Aversão à Incerteza está ligada à tolerância de uma sociedade em relação à ambiguidade, ou seja, o modo como se lida com o facto de o futuro não poder ser conhecido e de se tentar antecipar e controlar o futuro. A dimensão Masculinidade versus Feminilidade tem a ver com a distribuição de valores entre géneros. Uma pontuação alta (masculina) nesta dimensão indica que a sociedade é motivada pela competição e pelo êxito. Uma pontuação baixa (feminina) revela que os valores dominantes se centram no cuidado com os outros e na qualidade de vida. Esta dimensão estabelece uma divisão entre querer ser o melhor - masculinidade - ou gostar do que se faz e destacar a qualidade de vida - feminilidade.

A dimensão Individualismo versus Coletivismo está relacionada com o grau de interdependência que uma sociedade mantém entre os seus membros e a definição da autoimagem das pessoas em termos do "eu" ou do "nós". Nas sociedades individualistas as pessoas devem cuidar de si mesmas e da sua família direta. Nas sociedades coletivistas, as pessoas pertencem a grupos que cuidam delas em troca da lealdade aos mesmos.

A dimensão Orientação em Longo e Curto Prazo diz respeito ao modo como as sociedades se focam no passado, presente ou futuro. A orientação a longo prazo está relacionada com os ensinamentos de Confúcio na medida em que "representa um foco na orientação para o futuro presente nas máximas de Confúcio" (p. 26) em vez de ver o mundo através de um ponto de vista histórico convencional de curto prazo.

Em Hofstede Insights (2018) ${ }^{1}$ surge uma nova dimensão, Indulgência versus Restrição, que se refere à forma como as crianças são socializadas. Esta

1 Hofstede Insights é um website criado em 2017 que resulta da fusão entre as instituições ITIM International e The Hofstede Centre. Esta plataforma serve como instrumento para a construção contínua do trabalho do professor Geert Hofstede: https://www.hofstede-insights.com/about-us/ (Recuperado a 12 de maio de 2019).
A cultura chinesa: das dimensões culturais de Hofstede às perspectivas asiacêntricas de comunicação

Manuel Duarte João Pires 
Dossier América Latina: la iniciativa china de la Franja y la Ruta dimensão considera as culturas indulgentes ou restritas com base na forma como as pessoas tentam controlar os seus desejos e impulsos, tendo em conta a maneira como foram educadas. Um controlo mais fraco ou permissivo é denominado Indulgência e um controlo mais forte ou rígido é considerado Restrição.

Através de Hofstede Insights (2018) é possível pesquisar os resultados destas seis dimensões para cada país. Os indicadores relativos à China revelam que é uma sociedade onde as desigualdades entre as pessoas são aceitáveis, o relacionamento entre subordinado e superior tende a ser polarizado e existe uma aceitação das formas de poder exercido pelos superiores. As pessoas são influenciadas pela autoridade formal e em geral são otimistas em relação à capacidade de liderança e iniciativa de quem dirige as instituições.

No que respeita a evitar a incerteza a China é apresentada como uma sociedade pragmática que se sente confortável com a ambiguidade e por isso apresenta níveis baixos de Aversão à Incerteza.

Os resultados indicam também que a China é uma cultura altamente coletivista onde as pessoas agem no interesse do grupo e não de si mesmas. Os relacionamentos pessoais (família, amigos, colegas de trabalho) fazem parte de uma rede de grupos fechados e são determinantes a vários níveis, inclusive a nível profissional ou empresarial, denotando-se alguma frieza para com os grupos externos aos quais não pertencem.

Em relação a este binómio entre coletivismo e individualismo, Triandis $(1995 ; 2001)$ considera ser a diferença cultural mais significativa entre culturas. Triandis (2001) estabelece uma certa demarcação geográfica, associando a diferentes espaços do mundo uma determinada concepção e forma de estar na sociedade. A Europa do Norte (e Ocidental) e América do Norte de um lado (sociedades individualistas) e a Ásia, África e América do Sul do outro (sociedades coletivistas):

(...) nas culturas individualistas, como as da Europa do Norte e Ocidental e da América do Norte, as pessoas privilegiam elementos do eu pessoal (por exemplo, "Eu sou amável"). As pessoas de culturas coletivistas, como as da Ásia, África e América do Sul, tendem a usar elementos do eu coletivo (por exemplo, "a minha família pensa que eu sou amável"). (Triandis, 2001, p. 908)

Nas culturas coletivistas as pessoas são interdependentes dentro dos seus grupos e definem os seus comportamentos com base nas normas do grupo. Nas sociedades individualistas as pessoas são autónomas e independentes dos seus grupos, dão prioridade aos seus objetivos pessoais e comportam-se com base nas suas atitudes e não tanto nas normas do seu grupo. Não obstante, o autor refere que nem todas as pessoas dentro de uma determinada cultura se identificam ou têm necessariamente de seguir os pressupostos e os ideais nas quais estas se fundamentam. As pessoas "experimentam amostras de estrutu- 
ras cognitivas individualistas e coletivistas, dependendo da situação" (Triandis, 2001, p. 909).

A quinta dimensão cultural presente em Hofstede Insights (2018) diz respeito ao binómio Masculinidade versus Feminilidade e adianta que a China é uma sociedade masculina orientada para o sucesso onde a necessidade de alcançar o êxito pode ser exemplificada pelo facto de muitos chineses sacrificarem as prioridades da família e do lazer em prol do trabalho e pela intensa competição dos estudantes chineses com as notas e classificações dos exames.

Em relação à dimensão Orientação em Longo e Curto Prazo os resultados revelam que a China é uma sociedade de longo prazo, na qual a persistência, a perseverança e a manutenção da ordem são fundamentais. Os chineses demonstram uma capacidade de adaptação, uma forte propensão para investir e muita perseverança na obtenção de resultados. Os relacionamentos são definidos pelo estatuto social e as pessoas acreditam que o conceito de verdade é flexível de acordo com cada situação ou contexto em particular.

Por último, a China é considerada uma sociedade restrita pois obtém uma baixa pontuação na dimensão Indulgência. Segundo Hofstede Insights (2018), as sociedades restritas não enfatizam muito o tempo de lazer e as pessoas têm a percepção de que as suas ações são restringidas pelas normas sociais, privilegiando comportamentos de comedimento e discrição e evitando expressarem efusivamente os seus desejos e emoções.

Em conclusão, segundo as dimensões culturais de Hofstede, a China tem uma sociedade onde existe um grande distanciamento em relação ao poder e uma generalizada aceitação da desigualdade; é uma sociedade pragmática que se sente confortável com a ambiguidade e a incerteza do futuro; é uma sociedade masculina orientada para o trabalho e para o sucesso; tem um sentido coletivista onde as relações pessoais se sobrepõem e as normas dos grupos determinam os comportamentos dos seus elementos; é orientada para o longo prazo, guiada por valores como a perseverança, a manutenção da ordem e o respeito pelos estatutos sociais; e é também uma sociedade onde as normas sociais tendem a restringir as atitudes das pessoas e a recomendar humildade e comedimento.

\section{Análise crítica das dimensões culturais de Hofstede}

Diversos autores como Yeh (1988), McSweeney (2002), Saint-Jacques (2012) ou Miike (2012) apontam críticas a esta forma de Hofstede de medir e comparar culturas pelo facto de efetuar generalizações excessivas, não ter em conta as mudanças sociais que ocorrem nas sociedades e aplicar os mesmos (e reduzidos) indicadores para estudar culturas tão diversas.

Segundo Yeh (1988), existem problemas de conceptualização, inadequação das dimensões aplicadas e problemas na explicação dos resultados. Yeh (1988) e McSweeney (2012) consideram que uma vez que os questionários
A cultura chinesa: das dimensões culturais de Hofstede às perspectivas asiacêntricas de comunicação

Manuel Duarte João Pires 
Dossier América Latina: la iniciativa china de la Franja y la Ruta nos quais se baseiam as conclusões de Hofstede foram originalmente dirigidos a trabalhadores de diferentes nacionalidades dentro da empresa IBM - na qual o autor trabalhava - entre o final dos anos 60 e início da década de 70, os resultados são muito vagos, a amostra é muito pequena para alguns países, os trabalhadores têm perfis académicos similares e provêm de classes sociais semelhantes. Estes autores consideram ainda que a pesquisa não foi desenhada para explorar diferenças entre países, consistindo num estudo interno da IBM que apresenta conclusões muito gerais e com "pouco valor científico" (Yeh, 1988 , p. 150). Yeh e McSweeney indicam ainda que os países não são as melhores unidades para analisar as diferenças culturais, as dimensões apresentadas não são suficientes para determinar todos os aspectos culturais e os resultados desatualizam-se porque se trata de um "estudo estático que não tem em conta o dinamismo cultural, as mudanças de valores e as mudanças económicas, sociais e organizacionais na sociedade" (Yeh, 1988, p. 151).

Saint-Jacques (2012) entende que o estudo de Hofstede está ultrapassado porque os questionários dirigidos a um pequeno grupo de participantes de uma dada sociedade, "não se adaptam à investigação em compreensão intercultural” (p.46) porque as culturas não são entidades homogéneas ou estáveis e têm uma natureza cada vez mais híbrida. Saint-Jacques dá o exemplo do Japão, sobre o qual diversos estudos revelam que para as gerações mais novas o indivíduo se tornou mais importante que o grupo, as taxas de divórcios e de jovens que não pretendem constituir família aumentaram de modo que não se pode simplificar o Japão como uma cultura coletivista (p. 50). Huang (2000) possui uma opinião semelhante em relação à sociedade chinesa, alertando também para os perigos dos "estereótipos comuns sobre sociedades coletivistas" (p. 121).

Saint-Jacques (2012) defende que a investigação intercultural fundada nas dimensões culturais tradicionais não é uma via para a compreensão intercultural porque "não se pode estudar a diversidade através de dimensões culturais universais ou conjuntos fixos de atributos polares" (p. 48). O autor defende que a generalização não faz parte do caminho em direção ao entendimento intercultural porque a globalização não é sobre homogeneização, mas sobre diversidade ou diversidades. A globalização deve servir para a promoção da diversidade cultural e das diversidades que caracterizam as culturas. Como tal, os pesquisadores devem contribuir para a diversidade de conhecimentos e valores em vez de forçar a homogeneidade ou defender teorias monoculturais.

Estes argumentos são partilhados por Miike (2012) que também afirma que a investigação em comunicação intercultural deve promover a diversidade pois os conflitos no mundo não surgem da diferença cultural em si, mas da ignorância dessa diferença. A ignorância da diversidade cultural, e não a própria diversidade cultural, é uma fonte de desarmonia e conflito na aldeia global. No caso concreto da Ásia, Miike diz que as nações asiáticas não podem ser analisadas à luz de dimensões culturais estáticas, pois são feitas de pluralidade, diversidade e dinamismo: 
As nações asiáticas são sociedades plurais. A Ásia é diversificada e dinâmica. É uma região de complexidade cultural, continuidade e mudança. Embora o termo signifique uma certa localização geográfica no mundo, designa uma luta histórica e política comum contra o imperialismo ocidental e o colonialismo, e implica fundações religiosas-filosóficas compartilhadas e herança cultural. (Miike, 2012, p. 76, tradução M. Ochab)

Ao longo das últimas décadas as dimensões culturais de Hofstede têm sido instrumentos bastante utilizados por investigadores de todo o mundo para analisar e comparar sociedades ou culturas (McSweeney, 2002; Miike, 2012; Saint-Jacques, 2012). Este trabalho não pretende mostrar discordância ou questionar a validade das teorias e dos modelos de Hofstede ou Triandis para a análise das culturas de diferentes países. No entanto, com o objetivo de evitar eventuais generalizações decorrentes do estudo de diferentes culturas sob os mesmos pressupostos teóricos, esta investigação aborda alguns princípios importantes da cultura chinesa através da análise de alguns estudos publicados por autores asiáticos sobre o tema.

\section{A cultura chinesa segundo o conceito de comunicação}

Tendo como ponto de partida os cinco temas que, segundo Miike (2012), "compõem coletivamente um retrato asiacêntrico da humanidade e da comunicação” (p. 71), serão abordadas algumas características basilares da comunicação na cultura chinesa. Para Miike existem "cinco proposições interligadas" (p. 71) através das quais o conceito de comunicação deve ser interpretado do ponto de vista asiático. Estas cinco proposições são as seguintes:

\section{Comunicação como processo que relembra os seres humanos para a interdependência e inter-relação do universo}

Segundo Miike nada nem ninguém no universo vive isolado, pois a comunicação é um processo em que as pessoas fazem parte de uma rede em constante expansão de relacionamentos no tempo e no espaço. A cosmovisão asiática pressupõe uma constante comunicação com a "família humana, a natureza e até o sobrenatural ou mundo dos espíritos" (p. 72).

Para Chang (2007), na filosofia e na cultura chinesa os relacionamentos e a harmonia são a chave para a compreensão da comunicação na Ásia. Enquanto a interdependência dos relacionamentos é a comunicação em processo, a harmonia é o objetivo último da comunicação. Para Chang o objetivo da comunicação asiática é alcançar um estado harmonioso das relações humanas.

Chang (2008) reforça a importância da interdependência das relações sociais para explicar o importante conceito de face na cultura chinesa. Para
A cultura chinesa: das dimensões culturais de Hofstede às perspectivas asiacêntricas de comunicação

Manuel Duarte João Pires 
Dossier América Latina: la iniciativa china de la Franja y la Ruta
Chang não existe um conceito de face ou de honra individualizado na cultura chinesa: "não podemos usar indivíduos como unidade de análise; em vez disso, devemos examinar os indivíduos em inter-relações” (p. 301). Chang (2008) dá o exemplo de alguém que após migrar da sua aldeia regresse sem ter conseguido almejar sucesso pessoal ou profissional. Por esse motivo, esse indivíduo perde a face assim como os seus familiares e restantes membros dessa comunidade. Como tal o conceito de face é "comunal e moral" (p. 302), pois é indelevelmente extensível a uma família ou comunidade. Deste modo, Chang define a comunicação interpessoal chinesa como um "jogo de interrelações” (p. 305) que sofrem mudanças ao longo do tempo. O autor exemplifica com as mudanças nos valores tradicionais da relação entre pais e filhos das famílias chinesas em que os pais não se apresentam tanto como figuras de autoridade inquestionável, revelando atualmente mais interesse e abertura em ouvir e compreender os filhos.

Jia e Huang (2008) consideram que a visão de individualidade, isto é, o "eu" na cultura chinesa difere da visão ocidental, pois é basicamente conceptualizado em relação aos outros. É de natureza social, relacional e interdependente, por isso a expressão da individualidade está intimamente ligada aos relacionamentos e não ao isolamento. Os asiáticos buscam relações harmoniosas pois um ser humano é percebido como um ser social, profundamente enraizado nas redes de relacionamento: "A relação é um aspecto inseparável de si próprio" (Jia \& Huang, 2008, p. 145).

\section{Comunicação como processo pelo qual se reduz a individualidade e o egocentrismo}

Segundo Miike (2012), esta premissa contrasta com o conceito ocidental onde a comunicação é entendida como um "processo pelo qual se reforça a autoestima ou os interesses pessoais" (p. 72). Miike argumenta que, devido ao lado relacional e interdependente da comunicação, segundo os ensinamentos de Confúcio, esta deve servir para reduzir a individualidade e o egocentrismo através da autodisciplina e do desenvolvimento pessoal. Deste modo, os asiáticos são motivados para se cultivarem, disciplinarem e trabalharem arduamente através dos exemplos daqueles que adquiriram competências destacáveis ao longo de anos de prática ou de pessoas que vingaram na vida lutando contra todas as probabilidades. Esta redução da individualidade está ligada à primeira dimensão referida anteriormente de comunicação orientada para a relação de interdependência com os outros. Por este motivo Chang (2008) explica que, enquanto a comunicação interpessoal para os norte-americanos é racional e baseada nas particularidades de cada indivíduo (self-oriented), na cultura chinesa é emocional e baseada nas relações com os outros (other-directed) (p. 299).

Segundo Jia e Huang (2008), na cultura chinesa para estabelecer relações harmoniosas é importante ser flexível e transigente, o que conduz a um estilo 
indireto na interação interpessoal. Jia e Huang dão o exemplo dos norte-americanos que, ao orientarem-se pela sua individualidade (self-oriented), interpretam a inibição da expressão individual como um problema ou um obstáculo a uma comunicação franca e desimpedida. Por isso, as relações interpessoais são mais diretas (p. 132). Por outro lado, os chineses são particularmente sensíveis ao que devem dizer e como dizer nas diferentes relações interpessoais de modo a proteger a própria face e a sensibilidade dos outros. Os outros na interação social são mais importantes do que a própria individualidade, por isso o que é dito por alguém é muitas vezes "menos importante do que quem diz para quem e do que a forma como o diz" (p. 146). Jia e Huang reforçam a importância do lado relacional e coletivo da individualidade da seguinte forma: "a própria pessoa existe nas relações. A realização de um bom relacionamento/ harmonia é o objetivo final da auto-atualização" (p. 146).

A importância dos outros em relação à individualidade é visível, por exemplo, na forma como os alunos chineses falam das escolhas do seu percurso académico. Quando questionados sobre o motivo pelo qual escolheram a licenciatura que frequentam, é comum começarem a resposta por "os meus pais consideraram que...". Não só sobre a licenciatura, mas também sobre outros assuntos como as motivações para estudar Português, a escolha do país para fazer intercâmbio ou a área profissional em que pretendem trabalhar no futuro. É muito habitual começarem as respostas pela opinião dos pais, sendo que às vezes nem sequer fica claro quais são as suas próprias motivações ou decisões. Uma vez que estas características da comunicação da cultura chinesa se encontram profundamente inter-relacionadas, a inibição da individualidade está também intrinsecamente ligada à sensibilidade e orientação para os outros expressas na terceira premissa de Miike.

\section{Comunicação como processo ligado aos sentidos e sentimentos de todos os seres}

Miike (2012) afirma que esta proposição está particularmente ligada ao tema asiático de viver orientado para os outros (other-directness), pois a sensibilidade em relação aos sentimentos dos outros concidadãos reveste-se de grande importância. Miike argumenta que os sentimentos e as emoções são qualidades igualmente ou ainda mais valorizadas do que a razão no entendimento asiático da comunicação e da humanidade. $\mathrm{O}$ autor defende que a sensibilidade, mais do que a racionalidade, é uma característica da humanidade, pois através dos sentidos e sentimentos os seres humanos cumprem a sua existência em relação aos outros seres do universo. Desta forma, a visão asiática não encoraja uma comunicação centrada na expressão da afetividade dos falantes, mas recomenda comedimento ou reserva na expressão de emoções de modo a proteger os sentimentos dos outros. $\mathrm{Na}$ interação, os receptores da mensagem devem interpretar ou ler as "dinâmicas emocionais" de quem emite
A cultura chinesa: das dimensões culturais de Hofstede às perspectivas asiacêntricas de comunicação

Manuel Duarte João Pires 
Dossier América Latina: la iniciativa china de la Franja y la Ruta as mensagens, pois para se ser "comunicativamente ativo na perspectiva asiática" é necessário ser "perceptivo, receptivo e introspectivo" (p. 73).

Esta orientação para os outros relaciona-se com a questão de se ser indireto ou implícito na comunicação. Wang (2008), a propósito das diferenças entre as culturas cuja comunicação se processa de forma mais direta ou indireta, afirma que algumas culturas como a chinesa tendem a usar uma linguagem indireta, não conflituosa e vaga, confiando nas competências do ouvinte ou do leitor de captar o significado do contexto. Por outro lado, outras culturas praticam uma abordagem mais direta, conflituosa e explícita para garantir que o ouvinte recebe a mensagem exatamente como foi enviada. No seu estudo sobre situações de interação entre a comunidade inglesa e chinesa em Hong Kong, Wang aborda a tendência para evitar dizer "não" de forma explícita por parte dos interlocutores chineses. Entre os vários exemplos demonstrados, Wang apresenta o caso de um cidadão inglês que está a combinar uma reunião com um cidadão chinês para uma data em que este último já tem a agenda ocupada e não pretende que a reunião seja realizada nessa data. No entanto, para não ferir a sensibilidade do outro nunca diz explicitamente que está indisponível, ao invés, enumera algumas tarefas e compromissos familiares que pretende realizar nesse dia. Como o interlocutor inglês não compreende estas razões de forma suficientemente explícita para mudar ou cancelar a reunião - e o interlocutor chinês não pretende ferir as susceptibilidades do outro dizendo diretamente que está ocupado nesse dia - a reunião acabou por ficar marcada para essa mesma (inconveniente) data.

Os significados das mensagens são reconhecidos e construídos em conjunto pelo emissor e pelo receptor, dependendo do contexto e da situação de interação. Deste modo, a comunicação indireta contribui para a construção contínua do contexto à medida que a conversa avança e esta construção de contexto ajuda a inferência do receptor. Na comunicação na cultura chinesa o significado da mensagem do emissor, "oculto no nível literal”, é compreendido pelo receptor "através do processo de inferência" (Cheng e Warren, 2003, p. 397).

Jia e Huang (2008) consideram que a comunicação implícita revela a intenção do locutor de uma forma vaga e indireta, ou seja, sugerida, subestimada ou mesmo não verbalizada. Muitas vezes a intenção do falante só pode ser entendida através da intuição "construída através de anos de contacto pessoal" (p. 137), enquanto a comunicação explícita revela a intenção do falante de forma clara e verbal. Segundo Jia e Huang, o falante implícito evita verbalizar diretamente a sua intenção. Por isso, no caso chinês, a comunicação é orientada pelo ouvinte, uma vez que o ouvinte é responsável por discernir o significado através da intuição ou das referências contextuais do falante (p. 138).

$O$ facto de na cultura chinesa não ser conveniente ser direto na forma de interagir com os outros para resolver assuntos, negociar ou solicitar um pedido, está expresso no estudo de Jia e Huang (2008) sobre a forma de efetuar pedidos (requests) entre cidadãos americanos e cidadãos chineses: 
Por agir de forma implícita, os chineses podem deixar a impressão de serem "falsos" e "indignos de confiança" nos americanos. Os americanos podem não deixar melhor impressão sobre os chineses - os chineses podem reclamar dos americanos por serem muito diretos e sem reservas em seu pedido. Os americanos podem deixar a impressão de serem contundentes, indelicados e até rudes com os chineses. (Jia \& Huang, 2008, p. 139, tradução M. Ochab)

No estudo sobre a comunicação intercultural entre cidadãos americanos e chineses elaborado por Wang (2008) são enumerados alguns conselhos para melhor compreensão e entendimento mútuo e o autor afirma que os cidadãos chineses devem compreender que "as perguntas e observações diretas não têm necessariamente o objetivo de ofender, mas de esclarecer e avançar promover objetivos comuns" (Wang, 2008, p. 154). Por seu turno, Tannen (1985), ao abordar as dificuldades e sinuosidades da comunicação entre culturas, refere que o falante chinês se pauta por ser indireto (indirectness) e de interpretar o "ser-se direto" como uma característica rude ou infantil (Tannen, 1985, p. 211).

Ao longo dos anos de vivência na China constato esta dificuldade em ser direto ou em dizer "não" aos cidadãos chineses. Quando a resposta a uma mensagem é negativa, muitas vezes optam simplesmente por não responder para não dar uma resposta negativa ou então, caso se insista, optam por respostas vagas como "vamos ver se será possível" ou "não estou muito optimista em relação a esse assunto”. Por estas razões, é necessário saber ler nas entrelinhas para perceber as particularidades da forma de comunicação na cultura chinesa. A orientação para o outro e a comunicação implícita e indireta de modo a proteger susceptibilidades está interligada com a responsabilidade e reciprocidade do processo de comunicação.

\section{Comunicação como dever de responsabilidade e reciprocidade}

Miike (2012) entende a comunicação na Ásia como um processo em que se recebe e se devolve a dívida para com os outros e para com a natureza, e em que a existência depende de todos os outros seres. Na visão asiática do mundo as pessoas devem sentir gratidão em relação aos concidadãos, à natureza e aos espíritos ancestrais. Para Miike a comunicação faz-se de amabilidade, gratidão e empatia, pois assume uma "perspectiva circular no tempo e no espaço" (p. 74) em que os seres humanos devem pagar a sua dívida de gratidão em relação aos outros, pelo que se não o fizerem na vida presente esta dívida de gratidão é transmitida às gerações futuras.

Para Chang (2008) existem dois conceitos fundamentais para a comunicação no contexto cultural chinês: a reciprocidade das relações sociais (guanxi) e a face (mianzi) ou respeito pelos sentimentos humanos. Segundo Chang, estes valores são usados para resolver conflitos interpessoais e alcançar objetivos práticos no dia a dia. No contexto chinês o guanxi designa a "complexa rede de
A cultura chinesa: das dimensões culturais de Hofstede às perspectivas asiacêntricas de comunicação Manuel Duarte João Pires 
Dossier América Latina: la iniciativa china de la Franja y la Ruta relações indispensáveis ao funcionamento social, político e organizacional" na China (p. 310). Quando alguém faz um pedido a um detentor de recursos, este considera o tipo de relação existente entre ambos (guanxi) para assim adoptar um comportamento de acordo com regras específicas de interação social.

Uma vez iniciado, o guanxi deve ser mantido, pois os indivíduos (ou organizações) ao relacionarem-se com uma ou mais pessoas em comum vão formando uma rede comum e extensa de "importância vital baseada na reciprocidade e confiança” (Trigo, 2006, p. 19). O conceito de guanxi é um fator decisivo e normativo na sociedade chinesa construído através de um processo estratégico de modo a controlar recursos interpessoais, poder e estatuto social. Por este motivo é visto também como uma oportunidade de conseguir o que se precisa. Por exemplo, encontrar um emprego, comprar um carro ou colocar o filho numa escola melhor, são ações frequentemente realizadas através da reciprocidade das relações sociais.

É por este motivo que os alunos da Universidade de Sun-yat Sen por vezes me dizem com algum sarcasmo que para o futuro deles é muito mais importante terem os guanxi’s (contatos) certos do que uma graduação universitária.

No que respeita ao conceito de face (mianzi) na cultura chinesa, Ho (1976) defende que as ações com vista a "obter face" não são uma condição necessária para os indivíduos, no entanto, perder a face é uma questão séria que afeta a capacidade de alguém desempenhar as suas funções na sociedade. Ho explica que a face se perde quando o indivíduo, por meio das suas ações ou das ações de pessoas intimamente ligadas a si, "falha em corresponder às exigências esperadas em virtude da posição social que ocupa” (p. 867).

A reciprocidade é inerente ao conceito de face, na qual um poder restritivo e coercivo é exercido sobre cada membro da rede social e em que as ações do indivíduo, longe de serem conduzidas pelos seus próprios desejos, são ditadas pela necessidade de atender às expectativas dos outros.

Como as expectativas sociais são recíprocas por natureza, os conflitos surgem quando existe uma discrepância entre o que uma pessoa espera ou reivindica dos outros e o que outros lhe concedem. A face do indivíduo pode ser ameaçada por ações que não são dirigidas diretamente a si, tais como uma falta de deferência mostrada por outros aos seus familiares, amigos ou subordinados. Ho alerta para as diferenças a nível do comportamento humano mais centrado no indivíduo nas culturas ocidentais e com foco na interdependência e reciprocidade na cultura chinesa:

O conceito de face reflete duas orientações fundamentalmente diferentes na visão do comportamento humano: a orientação ocidental, com a sua preocupação com o indivíduo, e a orientação chinesa, que coloca o acento na reciprocidade de obrigações, dependência e proteção da estima. Estas duas orientações não precisam nem devem ser consideradas como mutuamente exclusivas. (Ho, 1976, p. 882, tradução M. Ochab) 
Na comunicação chinesa a face e a reciprocidade são elementos a ter em conta indispensáveis para uma interação humana harmoniosa porque pressupõem um sincero apreço em relação às partes em interação e uma tendência para omitir a individualidade na comunicação. Isto não significa que não ocorram conflitos, no entanto, é mais provável que o povo chinês se envolva em conflitos com estranhos do que com pessoas do círculo mais próximo. Segundo Chen (2004), isso deve-se à ênfase nas relações particulares na sociedade chinesa, o que leva a uma nítida distinção entre membros dos grupos internos e externos (in-group/out-group). Ao mesmo tempo que se desenvolve uma forte relação com os elementos dos grupos internos, por vezes desconfiase dos membros dos grupos externos, razão pela qual "demonstrar respeito, reciprocidade e sinceridade para com estranhos tende a ser menos importante na comunicação chinesa" (Chen, 2004, p. 31).

Para Xiao e Chen (2009) o autocontrolo, a expressão indireta e a proteção da face são características basilares da cultura chinesa que se interligam para promover a harmonia entre os diversos elementos da humanidade. O conceito de face remete para esta interligação ou interdependência em todas as relações ou interações, isto é, a necessidade de proteger ou enaltecer a nossa face, mas também a face dos outros, num contexto que respeita a posição ou hierarquia que cada um representa na sociedade e que tem como objetivo último a manutenção da harmonia.

\section{Comunicação como processo pelo qual se moraliza e harmoniza o universo}

Miike (2012) argumenta que a ênfase axiológica asiática está ligada à ordem social e, em última análise, à ordem do universo, por isso "a comunicação deve preconizar a integridade moral e a harmonia" (p. 74). A comunicação deve ser estabelecida em nome do benefício dos outros e não em nome do auto-interesse, evitando a hostilidade para com os outros e o uso de linguagem direta ou agressiva.

Segundo Xiao e Chen (2009), através de séculos de prática, a China confuciana desenvolveu um número incontável de regras específicas para regular as ações das pessoas de modo a garantir uma comunicação moral e sincera. Confúcio vê o estudo da comunicação como essencialmente um curso de cultivo moral (p. 71). Assim, na China confucionista, a competência comunicativa é sempre estudada e cultivada em associação com um programa mais amplo de educação moral.

O ensino dos valores morais é uma das características que um bom professor deve possuir segundo o provérbio chinês “传道授业解惑也” (Zhang et al., 2013, p. 2). Este provérbio refere as responsabilidades de um professor para com os seus alunos, nomeadamente, transmitir valores morais, conhecimentos e esclarecer as dúvidas dos alunos. Zhang et al. (2013) afirmam que se
A cultura chinesa: das dimensões culturais de Hofstede às perspectivas asiacêntricas de comunicação

Manuel Duarte João Pires 
Dossier América Latina: la iniciativa china de la Franja y la Ruta o professor descurar algum destes valores, não corrigir os erros ou não conseguir responder às questões dos alunos, tal pode ser interpretado como sinal de fraqueza e até constituir uma desonra para a sua face. A importância da moral está também expressa nos programas das licenciaturas de Português das universidades chinesas. Os programas dos cursos começam com um parágrafo que alude à importância do curso universitário enquanto meio para o cultivo da moral bem como da saúde física e intelectual.

Para Chen (2004) todas as ações humanas visam alcançar a harmonia pelo que os padrões morais e as regras para os comportamentos adequados são gerados com base no conceito de harmonia. Chen argumenta que o conceito de keqi (cortesia) representa a harmonia na comunicação chinesa, ou seja, manter uma atitude educada e discreta é uma forma de sustentar um relacionamento harmonioso na comunicação chinesa.

A harmonia é um princípio orientador do comportamento na comunicação chinesa e que faz da comunicação chinesa um processo único. A cultura chinesa privilegia a preservação da harmonia e tende a evitar atitudes que a possam pôr em causa como a comunicação direta ou a discussão aberta. Para os chineses a necessidade de manter a harmonia interpessoal é uma condição prévia para a resolução de qualquer conflito. Desta forma, fomenta-se a discrição e o uso de uma linguagem indireta que promova o equilíbrio e a reciprocidade. Para a interação com os cidadãos e instituições chinesas é necessário ter em consideração estes princípios e sobretudo querer conhecer e procurar ir além da generalização através de um posicionamento de abertura e interação intercultural.

\section{A importância da interação e das competências interculturais}

O Relatório Mundial da UNESCO (2009) considera que num mundo culturalmente diverso é necessário analisar as diversas formas pelas quais as culturas se relacionam e adquirir um maior conhecimento dos valores que partilham e dos seus objetivos comuns. A base para um diálogo intercultural frutífero está no "reconhecimento da igual dignidade" (p. 10) dos indivíduos e pressupõe reconhecer e respeitar as diferentes formas de conhecimento e os seus modos de expressão, os valores, os costumes e as tradições. Unir esforços para estabelecer um contexto culturalmente saudável que facilite o diálogo e que permita a todos e a cada um expressar livremente a sua identidade cultural é a proposta da UNESCO (2009) quando defende que:

Nas sociedades multiculturais, um dos principais problemas reside na nossa capacidade para aprender a conviver. Por esse motivo, a educação multicultural deve ser complementada com uma educação intercultural. Sensibilizar as pessoas para a diversidade cultural, mais que uma assimilação de 
conteúdos, é uma questão de perspectivas, métodos e atitudes. A aceitação do outro é uma aptidão que se adquire com a prática. (UNESCO, 2009, p. 17)

A globalização da sociedade atual através das novas tecnologias faz não só com que as mudanças em curso na sociedade se processem de forma mais célere e imprevisível, mas também que se redimensionem as formas de estabelecer relações sociais e a própria organização social. Devido aos novos desafios das sociedades e do processo de globalização, a comunicação intercultural passou a ser um fenómeno importante, pois o entendimento dos sistemas sociais é cada vez mais necessário na vida atual.

Samovar, Porter e McDaniel (2012) argumentam que a relação entre pessoas de distintas culturas ocorre desde os princípios da humanidade. No entanto, no mundo em que vivemos, pautado pela busca de informação e pelo constante ritmo de vida comunicacional, nunca foi tão fácil para pessoas de diferentes nações ou culturas encontrarem-se e interagirem, devido ao desenvolvimento dos novos meios tecnológicos. A capacidade de relacionamento com pessoas de outras culturas, de falar outras línguas e de possuir valores e crenças diversificadas deve constituir atualmente um requisito comum para os cidadãos no atual contexto econômico mundial. Adquirir conhecimentos de comunicação intercultural e competências para comunicar de forma eficaz pode ajudar a mitigar problemas, estabelecer relações mais produtivas e alcançar uma relação mais harmoniosa entre povos. A comunicação intercultural, mais do que uma necessidade, é uma contingência ou imperativo dos tempos atuais, tal como expressam os autores quando afirmam que a globalização trouxe a percepção de que "as sociedades modernas devem aprender a cooperar a fim de prevenir a sua autodestruição" (p. 2).

De acordo com Tannen (1985), a comunicação intercultural é crucial para quase todos os tipos de encontros humanos, públicos e privados. Para Tannen, o destino das pessoas - e o destino do planeta - depende das negociações entre representantes de governos com diferentes pressupostos culturais e diferentes formas de comunicar. Para atingir quaisquer objetivos públicos ou privados, as pessoas precisam de interagir e cada vez mais as pessoas que se comunicam provêm de diversos backgrounds culturais. Por outro lado, à medida que a sociedade avança sobre pressupostos de globalização, a comunicação intercultural deixa de dizer respeito apenas a indivíduos falantes de diferentes línguas ou provenientes de diferentes países para incluir indivíduos do mesmo país ou grupo social, de diferentes classes sociais, regiões, idade e até género. Segundo a autora, $o$ alcance da comunicação intercultural não se circunscreve apenas ao diálogo intercultural propriamente dito, de uma ou mais culturas em presença, mas pode acontecer dentro da mesma cultura ou grupo social quando a interação é feita por indivíduos com identidades diferentes.

Segundo Alsina (1997), quando se comunica com alguém com uma identidade linguística e cultural semelhante não existe muita consciência do processo de comunicação, ao contrário do que acontece na comunicação intercul-
A cultura chinesa: das dimensões culturais de Hofstede às perspectivas asiacêntricas de comunicação

Manuel Duarte João Pires 
Dossier América Latina: la iniciativa china de la Franja y la Ruta tural em que existe a necessidade de se estar mais consciente do processo de comunicação devido às dificuldades próprias da comunicação intercultural. Na comunicação intercultural é necessário ter em conta que as interpretações "não são universais nem acrónicas" e que as pessoas de outras culturas fazem uso de "outros critérios interpretativos" (p. 14). Por isso, é necessário estar preparado para possíveis mal-entendidos, pois para compreender o Outro é preciso "compreender em primeiro lugar, a sua incompreensão" (p. 14), ou seja, compreender que o Outro vê o mundo sob um diferente background cultural e que a sua interpretação do contexto será influenciada pela sua própria cultura.

A produção de uma conduta intercultural adequada requer a produção de algumas "sinergias cognitivas e emotivas" (p. 15). Em termos cognitivos deve-se começar por ter consciência das próprias características culturais e dos próprios processos comunicativos para depois procurar conhecer as outras culturas e os seus processos de comunicação. O conhecimento do Outro juntamente com a autorreflexão ou o conhecimento de nós próprios contribuem para a redução do grau de incerteza presente na comunicação intercultural, assim como para a redução dos mal-entendidos e da tendência para a utilização de estereótipos fruto da falta de conhecimento das outras culturas.

O estereótipo consiste na simplificação da realidade quando existe pouca ou nenhuma informação sobre um tema e se utilizam tópicos ou lugares-comuns que permitem uma interpretação "socialmente aceitável, mas seguramente falsa” (Alsina, 1997, p. 17). O conhecimento mais profundo do Outro deve servir para superar os estereótipos e conduzir a uma busca por interpretações alternativas para lá dos lugares comuns. Para tal é necessário estabelecer um diálogo cultural crítico (e autocrítico) para conhecer as outras culturas e ver o mundo de outra perspectiva, para lá das representações sociais e culturais intrínsecas de cada cultura. A comunicação intercultural tem como objetivo eliminar os estereótipos negativos que cada cultura produz sobre as outras, estabelecendo uma mudança de mentalidade em relação à desumanização com que os povos construíram a representação de outros povos ao longo da história. Alsina resume os objetivos da comunicação intercultural da seguinte forma:

Durante demasiado tempo, os contatos entre culturas têm sido um espaço de confronto. A interculturalidade pretende que se tornem o mais rapidamente possível um espaço de negociação, que deve tender a ser um espaço de cooperação, para acabar por ser simplesmente um espaço de humanização. (Alsina, 1997, p. 20, tradução M. Ochab)

Para Jandt (2015), a comunicação intercultural relaciona-se com a interação entre pessoas de diversas culturas, sendo que a competência intercultural diz respeito às características ou competências (skills) necessárias para que cada indivíduo possa ser bem sucedido na comunicação e na interação cultu- 
ral. Segundo Jandt (2015), as características necessárias para adquirir competência intercultural dividem-se em quatro áreas principais: 1) personalidade - um comunicador eficaz deve conhecer-se bem, ter uma personalidade aberta e amigável e ter atitudes positivas para ser bem sucedido na comunicação intercultural; 2) competências de comunicação - possuir competências sociais de interação, ter procedimentos adequados e competências a nível da comunicação verbal e não-verbal; 3 ) competências psicológicas - ser capaz de lidar com os sentimentos que o choque cultural pode despertar como frustração, ambiguidade, stress ou alienação causados pelo contacto com novos ambientes; 4) consciência cultural - compreender os costumes sociais e o sistema social da cultura de acolhimento, uma vez que entender a forma de as pessoas interagirem e pensarem o mundo é determinante para uma comunicação eficaz com o Outro.

A aquisição da competência intercultural nunca é completa e perfeita na medida em que não é possível adquirir ou antecipar todo o conhecimento necessário para interagir com o Outro, tendo em conta a heterogeneidade de valores e identidades que compõem cada cultura. A competência intercultural não pressupõe a reprodução de um modelo ou a imitação do Outro, mas pressupõe o desenvolvimento de um conjunto de atitudes, conhecimentos, competências e valores para interpretar e interagir com as outras culturas.

As atitudes interculturais devem ter como base a vontade de relativizar os valores e comportamentos da própria cultura, assumindo que não são únicos nem necessariamente mais corretos, olhando-se para eles de uma forma distanciada. Byram et al., (2002) denominam esta atitude - de se tentar ver a própria cultura como outsider - como a capacidade de "descentrar" (p. 12). Para Byram et al., a predisposição para ir além da simples troca de informação e praticar uma atitude de curiosidade e abertura é a melhor forma de estabelecer um relacionamento empático com o Outro, independentemente de bandeiras, fronteiras ou credos.

Não se trata apenas de exaltar um conjunto de valores teóricos para a comunicação com o Outro, mas assumir ativamente que estes valores devem fazer parte da vivência dos cidadãos da sociedade global, principalmente daqueles que vivenciam contextos multiculturais. A competência intercultural requer uma postura participativa e dinâmica dos cidadãos para que as suas ações em relação aos aspetos sociais e culturais da sociedade possam ter um impacto global e para que se possam situar como cidadãos transnacionais que partilham um conjunto de valores humanísticos e universais como a interação com outras culturas e grupos sociais, a abordagem autocrítica ao diálogo intercultural, a liberdade ou a igualdade. Sem deixar de ter em conta as limitações práticas que muitas vezes se colocam à interação, avocar os princípios e as atitudes da comunicação intercultural são condições indispensáveis para compreender e chegar ao coração dos povos com um espírito de empatia, humanidade e universalidade do que o mundo carece nos dias que correm. Tal como conclui Alsina (2004): "De qualquer modo, é seguro que o processo
A cultura chinesa: das dimensões culturais de Hofstede às perspectivas asiacêntricas de comunicação

Manuel Duarte João Pires 
Dossier América Latina: la iniciativa china de la Franja y la Ruta no será lineal. Haverá conflitos e compromissos, avanços e contratempos. Em qualquer caso, estamos perante um fenómeno social, à escala global, que é inevitável" (Alsina, 2004, p. 62).

\section{Conclusões}

O significado do conceito de comunicação na cultura chinesa remete para a interdependência e inter-relação entre os vários elementos da sociedade; para o cultivo da autodisciplina; para o desenvolvimento de uma sensibilidade altruísta em relação aos sentimentos dos outros; para a necessidade de se ter presente a dívida em relação aos outros e agir em reciprocidade; para o uso da comunicação como meio de promover a harmonia e a moralidade. Estas cinco proposições representam uma base teórica da visão do mundo, do pensamento e da ação asiáticas. $\mathrm{O}$ autor argumenta que apesar da diversidade, complexidade e dinamismo das culturas asiáticas, estas partilham referências culturais e filosóficas além de um passado histórico e político de luta contra o imperialismo e colonialismo ocidental. Miike afirma que os "pontos de vista asiacêntricos não são superiores nem inferiores às concepções do mundo eurocêntricas, apenas são fundados em perspectivas diferentes” (p. 76). A autorreflexão e sobretudo o diálogo são determinantes para construir um sentido genuíno de comunidade global, uma comunicação intercultural autêntica e um verdadeiro respeito pela diversidade à escala mundial.

Tendo em conta a interação entre as várias culturas na sociedade global em que vivemos, a competência intercultural possibilita o enriquecimento mútuo de todas as culturas em presença e fomenta a ação e a interação em prol do respeito e da promoção da diversidade. A convivência harmoniosa entre cidadãos e culturas de um mundo em constante conflituosidade não pode ser criada se não através da aceitação, do diálogo, da comunicação e de um sentimento de abertura e empatia.

A literatura analisada é unânime em revelar que a harmonia é um valor primordial e transversal na cultura chinesa (Cheng e Warren, 2003; Chang, 2007; Jia e Huang, 2008; Chang, 2008; Wang, 2008). Sobre este assunto, Jullien (2010) afirma expressivamente que "enquanto para o pensamento europeu a liberdade é a última palavra, para o Extremo Oriente é a harmonia" (p. 5). Esta frase do sinólogo francês reflete também os tempos que a Europa e o Extremo Oriente vivem. Enquanto a Europa tem vindo a esforçar-se por preservar a liberdade como valor fundamental ainda que a harmonia esteja a ser alvo de diversos tipos de ameaças, por outro lado o Extremo-Oriente funda-se precisamente na harmonia como condição basilar de estabilidade e progresso ainda que por vezes algumas liberdades possam ser secundarizadas neste processo.

Atualmente a China marca a sua assertiva presença nos quatro cantos do mundo, o seu poderio económico e a forma gradual e harmoniosa como tem 
almejado progredir e desenvolver-se dentro e fora de portas permitem-lhe ser um país de referência a quem muitos outros recorrem para cooperar e crescer em várias áreas. No entanto, não condicente com esta ascensão e difusão da influência chinesa, prevalece ainda um assinalável desconhecimento em relação aos aspetos intrínsecos da cultura e da sociedade chinesa. Este estudo destaca a necessidade da comunicação intercultural, da empatia e da predisposição para conhecer e interagir como meios de desfazer estereótipos ou generalizações e de se estabelecerem ligações ainda mais sólidas e perenes entre a China e o resto do mundo.
A cultura chinesa: das dimensões culturais de Hofstede às perspectivas asiacêntricas de comunicação

Manuel Duarte João Pires

\section{Referências}

Alsina, R. (1997). Elementos para una comunicación intercultural. Revista CIDOB D’Afers Internacionals, no. 36, pp. 11-21.

Alsina, R. (2004). Cuestionamientos, características y miradas de la interculturalidad. Sphera Publica, no. 4, pp. 53-68.

Byram, M., Gribkova, B. \& Starkey, H. (2002). Developing the Intercultural Dimension in Language Teaching: a practical introduction for teachers. Language Policy Division. Council of Europe: Strasbourg.

Chang, C. (2007). Asian Communication Tradition and Communicative Rationality: Rethinking Methods for Intercultural Studies. Intercultural Communication Studies XVI, no. 2, pp. 71-80.

Chang, Y. Y. (2008). Cultural "Faces" of Interpersonal Communication in the U.S. and China. Intercultural Communication Studies XVII, no. 1, pp. 299-313.

Chen, G. M. (2004). The two faces of Chinese communication. Human Communication, no. 7, pp. 25-36.

Chen, G. M. \& Starosta, W. J. (2003). Asian approaches to human communication: A dialogue. Intercultural Communication Studies, no. 12 (4), pp. 1-15.

Cheng, J. (1994). Confucius as a Teacher. Philosophy of Confucius with Special Reference to its Educational Implications. ( $2^{\text {nd }}$ ed.). Beijing: Foreign Language Press.

Cheng, W. \& Warren, M. (2003). Indirectness, Inexplicitness and Vagueness Made Clearer. Pragmatics, no. 13 (3), pp. 381-400.

Hall, E. T. (1959). The Silent Language. Garden City, New York: Doubleday.

Hall, S. (2006). A Identidade cultural da pós-modernidade. (11 a ed.). (T. T. Silva, \& L. G. Louro, Trads.). Rio de Janeiro: DP\&A Editora.

Ho, D. (1976). On the Concept of Face. American Journal of Sociology, no. 81(4), pp. 867884.

Hofstede, G. (2001). Culture's Consequences: Comparing Values, Behaviors, Institutions and Organizations Across Nations ( $2^{\text {nd }}$ ed.). Thousand Oaks, CA: Sage.

Hofstede, G. (2012). Dimensionalizing Cultures: The Hofstede Model in Context. In: L. Samovar, R. E. Porter \& E. R. McDaniel (Eds.), Intercultural Communication. (13 ${ }^{\text {th }} \mathrm{ed}$., pp. 19-33). Boston: Wadsworth. 
Dossier América Latina: la iniciativa china de la Franja y la Ruta
Hofstede Insights. (2018). Country: China. Recuperado a 12 de maio de 2019, de Hofstede Insights: https://www.hofstede-insights.com/country/china/

Huang, L. (2000). The Chinese Way of Requesting Information in Intercultural Negotiation. Intercultural Communication Studies IX, no. 2, pp. 107-127.

Jandt, F. (2015). An Introduction to Intercultural Communication: Identities in a Global Community. ( $8^{\text {th }}$ ed.). Thousand Oaks, CA: Sage.

Jia, X. \& Huang, F. (2008). A Contrastive Study of Requests in Chinese and American Cultures. Intercultural Communication Studies XVII, no. 2, pp. 299-313.

Jullien, F. (29 de março de 2010). Entrevista Revista Cult. Mal-estar na Cultura. (Gunter Axt, Entrevistador). UFRGS, Brasil.

Kang, L. (2014). Globalization and Cultural Trends in China. Honolulu University of Hawaii Press.

Kulich, S. \& Wang, Y. (2015). Intercultural Communication in China. In J. Bennett (Ed.), The SAGE Encyclopedia of Intercultural Communication. (pp. 458-469). Thousand Oaks, CA: Sage.

McSweeney, B. (2002). The essentials of scholarship: A reply to Geert Hofstede. Human Relations, no. 55 (11), pp. 1363-1372.

Miike, Y. (2012). "Harmony without Uniformity": an Asiacentric Worldview and its Communicative Implications. In L. Samovar, R. E. Porter \& E. R. McDaniel (Eds.), Intercultural Communication. (13 $3^{\text {th }}$ ed., pp. 65-80). Boston: Wadsworth.

Saint-Jacques, B. (2012). International Communication in a Globalized World. In L. Samovar, R. E. Porter \& E. R. McDaniel (Eds.), Intercultural Communication. (13 ${ }^{\text {th }}$ ed., pp. 45-55). Boston: Wadsworth.

Samovar, L., Porter, R. E. \& McDaniel, E. R. (2012). Intercultural Communication. (13 $\left.{ }^{\text {th }} \mathrm{ed}\right)$. Boston: Wadsworth.

Tannen, D. (1985). Cross-cultural Communication. In T. v. Dijk (Ed.), Handbook of Discourse Analysis. (vol. 4, pp. 203-215). London \& Orlando: Academic Press.

Triandis, H. (1995). Individualism and collectivism. Boulder, CO: Westview Press.

Triandis, H. (2001). Individualism-Collectivism and Personality. Journal of Personality, no. 69(6), pp. 907-924.

Trigo, V. (2006). Cultura Económica Chinesa: Como Negociar na China? Lisboa: Edições Pedago.

UNESCO. (2009). Investir na diversidade cultural e no diálogo intercultural. Relatório Mundial da UNESCO. (Resumo). Paris: UNESCO - Organização das Nações Unidas para a Educação, a Ciência e a Cultura.

Wang, J. (2008). A Cross-cultural Study of Daily Communication between Chinese and American - From the Perspective of High Context and Low Context. Asian Social Science, no. 4(10), pp. 151-154.

Xiao, X. \& Chen, G. M. (2009). Communication competence and moral competence: a Confucian perspective. Journal of Multicultural Discourses, no. 4(1), pp. 61-74.

Yeh, R. (1988). On Hofstede's Treatment of Chinese and Japanese Values. Asian Pacific Journal of Management, no. 6(1), pp. 149-160.

Yao, X. (2000). An introduction to Confucianism. Cambridge: Cambridge University Press.

Zhang, D., Li, Y. \& Wang, Y. (2013). How Culturally Appropriate is the Communicative Approach with Reference to the Chinese Context? Creative Education, no. 4(10a), pp. 1-5. 